\title{
POINT OF CARE RAPID DIAGNOSTIC SCREENING FOR CHLAMYDIA TRACHOMATIS AMONG SEXUALLY ACTIVE ASYMPTOMATIC FEMALES IN OKADA, SOUTH-SOUTH NIGERIA
}

\author{
Akpoka, O.A.* ID, Okafor-Elenwo, E. J. ID , Nwadukwe, C. C. (ID), Okwu, M. U. (ID) \\ Address (es): \\ Department of Biological Sciences, College of Natural and Applied Sciences, Igbinedion University, Okada, Nigeria. \\ *Corresponding author: ausbones@gmail.com, ausbones@iuokada.edu.ng \\ (1)
}

https://doi.org/10.36547/be.2021.4.1.4-7

\section{ABSTRACT}

Introduction: Chlamydia is transmitted through sexual contact with the penis, vagina, mouth, or anus of an infected partner. It can be transmitted or acquired even without ejaculation. It can also be transmitted perinatally from an untreated mother to her baby during childbirth, resulting in ophthalmia neonatorum or pneumonia in some exposed infants.

Objective: The objective of this study was to screen for and determine the prevalence of Chlamydia trachomatis in asymptomatic sexually active women aged $16-33$ years with the aid of a point of care rapid test kits within a resource-limited setting.

Methods: In this study endocervical swab of a total of 170 female subjects between the ages of 16 to 33 were screened for Chlamydia trachomatis with two types of rapid test kits (Diaspot and Abon Rapid test kits for chlamydia). The subjects consisted of 140 study subjects and 30 control subjects attending the gynecological unit in Igbinedion University Teaching Hospital (IUTH) for other reasons, all subjects were random, sexually active, asymptomatic females and residents in Okada and its environs.

Results: A total of 11 subjects tested positive to chlamydia (7.85\%). The samples that tested positive for Chlamydia were from patients that were unmarried and students. The age groups with the highest prevalence were 22-28 (5.71\%) and 16-21 (2\%). $23.63 \%$ have had a previous history of STD and $26.47 \%$ had awareness of chlamydia infection. The ages group $(22$ - 27) had the highest level of awareness. The prevalence of Chlamydia trachomatis was consistent with their sexual lifestyles. Conclusion: Chlamydia screening should be a continuous public health intervention and screening programmes should ensure regular chlamydia screening for a high proportion of the target population. The methods for monitoring and ways to ensure standards are met should be adopted.

Keywords: Chlamydia, Rapid Test, Point of Care Testing, Sexually Transmitted Diseases, Chlamydia trachomatis, Okada

\section{INTRODUCTION}

Chlamydia is a common sexually transmitted disease (STD) by Chlamydia trachomatis. Human genital chlamydial infections and its clinical outcomes is the most common bacteria cause of STD. It is estimated to account for more than 90 of the 500 million annual incidences of STDs globally (CDC, 2017). Members of the major clinically relevant bacterial species of the genus Chlamydia cause endemic trachoma, genital and respiratory infections in humans (e.g. Chlamydia trachomatis and C. pneumoniae), as zoonotic pathogens (e.g. C. psittaci) or as veterinary pathogens (e.g. C. pecorum and C. abortus). Chlamydia trachomatis is an obligate intracellular bacterium with 15 immunotypes. The serovars A - C cause trachoma the world's most common preventable blinding disease which is endemic in Africa. An estimated 150 million people are infected worldwide, of which 6 million are visually impaired or irreversibly blinded (CDC, 2017). Serovars D-K cause genital tract infections, and serotypes L1-L3, causes Lymphogranuloma venereum LGV (associated with genital ulcer disease in tropical countries) (White, 2009). All Chlamydia species have a similar developmental cycle, comprising two prominent morphologically distinct forms the elementary body (non- infectious form) and reticulate body (infectious form) (Severin, 2006)

Chlamydia is transmitted through sexual contact with the penis, vagina, mouth, or anus of an infected partner with or without ejaculation and perinatally from an untreated mother during childbirth, resulting in ophthalmia neonatorum (conjunctivitis) or pneumonia in some exposed infants (Hoie et al., 2011). C. trachomatis infection are often asymptomatic, in many instances, primary infections are not recognized and only the sequelae caused by ascended, persisting agents are diagnosed. Approximately $50 \%$ of infected males and $80 \%$ of infected females are asymptomatic (Stamim et al., 2005). However, clinical syndromes could also be presented by both sexes at common epithelial sites, including the rectum and conjunctivae e.g. urethritis, epididymitis. Some clinical syndromes peculiar to women are pelvic inflammatory disease (PID) which is sequelae to infertility and chronic pain (Ingalis et al., 1995; Geisler et al., 2008), Cervicitis (Geisler et al., 2008; Detels et al., 2011; Marrazzo et al., 2005), Dysuria-pyuria syndrome due to urethritis (Landers et al., 2004) Perihepatitis Fitzhugh-Curtis syndrome (Marrazzo et al., 2005)), Complications of pregnancy (Rours et al., 2011) and Proctitis (including men who have sex with men (MSM)) (Ward et al., 2009). Patients with persistent symptoms with confirmed chlamydial infection after appropriate therapy with good adherence are usually not due to primary treatment but to recurrent infections (13). PID and tubal factor infertility with a prevalence of approximately $40 \%$ and $10 \%$ respectively are major complications of untreated female genital chlamydial infections thereby constituting an enormous morbidity and socioeconomic burden (CITATION 1 V 1033 CDC, 2017 ; O'Farrell et al., 2008).

Although, sexually active individuals with signs and symptoms consistent with the clinical syndromes associated with chlamydia are expected to undergo diagnostic testing for $C$. trachomatis, the often-asymptomatic nature of its infections makes routine screening absolutely necessary for high risk individuals. High risk individuals include women who are 25 years old or younger, pregnant, have new or many sexual partners, MSM patients with documented gonococcal infection, and patients with recent exposure, who present within one to two weeks of a potential or known exposure to chlamydia (e.g. sexual assault). The frequent asymptomatic insidious course of Chlamydia may also result in the initiation of chronic diseases. Silent infections have been known to become endemic in communities where it remained unnoticed for a very long time (Okoror et al., 2007)

Considering the magnitude and near epidemic state of ocular, genital and respiratory chlamydial infections in some populations, the continued spread in communities worldwide, and the economic stress on the healthcare system, several prevention and control strategies have been executed. These control and prevention measures includes mass screening and treatment, mass antibiotic treatment of at-risk populations, health education programs on prevention methods, and use of an efficacious vaccine as an immunoprophylaxis and preventive CITATION $14 \backslash 1033$ (Igietseme et al., 2011). Unfortunately, a number of these proposed or previously executed control and prevention measures are either very challenging to develop, impractical to execute or ineffectual in controlling the endemicity and spread in human populations CITATION $14 \backslash 1033$ (Igietseme et al., 2011)

The diagnostic technique of choice is the Nucleic Acid Amplification Testing (NAAT) due to its superior sensitivity, specificity and suitability for various types of samples like the vulvovaginal swabs and first void urine (FVU), endocervical (for women presenting with symptomatic cervicitis that undergo a speculum exam, or for high-risk women undergoing routine Pap smear) and urethral swab specimens. Other diagnostic methods where NAAT is unavailable are culture, antigen detection, and genetic probes. In a resource-limited setting, rapid tests (point of care) for chlamydia may be used for diagnosis. It is worthy of note that in the absence of specific diagnostic tests, the presumptive diagnosis of chlamydia is made when symptoms and signs of the clinical syndromes associated with chlamydia are present in young or sexually active patients CITATION $7 \backslash 1033$ (Marrazzo et al., 2005). If non-NAAT-based testing is used for diagnosis or adequate follow-up cannot be insured, patients with signs and symptoms consistent with chlamydia are given empiric therapy while awaiting results. 
NAAT is expensive for use in resource-limited settings and may not deliver same-day results. Against this backdrop, immunoassay-based tests which are based on monoclonal antibody binding of chlamydial antigens (chlamydia lipopolysaccharide) from self-collected samples were developed. These rapid tests are less expensive, simple to interpret and provide results within 30 minutes CITATION $16 \vee 1033$ (Greer \& Wendel, 2008). One of such is the Chlamydia Rapid Test (CRT) developed in 2009. This assay, when compared to NAAT had a sensitivity, specificity, positive predictive value, and negative predictive values of $83 \%$ (90/109), $99 \%$ percent (1085/1102), $84 \%$ (90/107), and $98 \%$ (1085/1104), respectively CITATION $17 \backslash 11033$ (Nadala et al., 2009) .

The public health significance of chlamydial infections is underscored by the huge socioeconomic burden of the ocular, genital and respiratory diseases. Chlamydia is not mostly screened for in Nigeria, hence the relative information about the frequencies of the organism is sparse CITATION $12 \backslash 1033$ (Okoror et al., 2007) . This study screened for Chlamydia trachomatis in asymptomatic sexually active females between the ages of 16-33 years in Okada (a resourcelimited setting) to determine the prevalence of chlamydia with two rapid diagnostic kits.

\section{MATERIALS AND METHODS}

\section{Study Area}

The study area was Ovia North-East Local Government Area, Edo State, Nigeria. Okada and its environs. Okada is headquartered to Ovia North-East Local Government Area. It has an area of $2,301 \mathrm{~km}^{2}$ and a population of 153,849 at the 2006 census. It is home to Igbinedion University with the student population contributing a sizeable percentage of the population. The occupation in Okada is predominantly farming and Lumbering.

\section{Subject and Population Size}

A total of One Hundred and Seventy (170) subjects were screened. The population comprised of Seventy (70) students, Seventy (70) non-student (study population) and thirty (30) female subjects attending the gynecology unit in Igbinedion University Teaching Hospital Okada (IUTH) (control population), participants in the study population were random sexually active healthy-looking female volunteers aged 16 - 33 years resident in Okada and its environs in Edo State; for all participants a standardized questionnaire which gathered demographic and other information such as age, marital status, number of sex partners and history of previous STD including awareness of chlamydia was completed.

\section{Sample Collection and Analysis}

Endocervical swabs were collected from One Hundred and Seventy (170) female subjects using sterile swabs provided in the kits. The subjects were educated on how to do a self-sample collection by inserting the swab into the endocervical canal, past the squamocolumnar junction until most of the cotton covered tip is no longer visible, then the swab firmly rotated at $360^{\circ}$ in one direction, allowed to stand for 15 seconds and withdrawn as stated in the manufactures packet insert. The tests were conducted immediately.

\section{Diagnostic Technique}

Non-culture technique (Rapid Test Kits) was used to test the collected swab samples. Materials provided in the kit included: test devices, test tubes, dropper tips, sterile female cervical swabs, reagent ' $\mathrm{A}$ ' $(0.2 \mathrm{M} \mathrm{NaOH})$, reagent ' $\mathrm{B}$ ' $(0.2 \mathrm{M}$ HCL), package insert, work station and quantitative pipette. The directions for use on the package insert was followed strictly.

\section{Data Analysis}

Data collected was analyzed using descriptive statistics and presented with tables and chart.

\section{Ethics}

A retrospective approval by the Ethical committee of Biological Sciences of Igbinedion University.

Informed Consent: Signed Informed consent

Funding: This research was funded by the authors.

\section{RESULTS}

A total of one hundred and seventy female cervical swab specimens were collected from healthy-looking women aged 16 to 33 years and 30 swab specimens (control) from women attending the gynecology unit of Igbinedion University Teaching Hospital (IUTH). They were all screened using a combination of two different brands of chlamydia rapid test kits (Diaspot and Abon). The results obtained from the two test kits were in agreement. $11(7.3 \%)$ samples tested positive to both brands of test kits while 139 (92.67\%) tested negative to both brands. The study population was made up of 70 students and 70 non-students but inhabitants of the study area). The control group was made of 30 female subject attending Igbinedion University Teaching Hospital for other gynecological issues previously screened and confirmed to be negative. 50 (71.4 $\%$ ) of the student population had multiple sexual partners while the non-students had only one partner. Table 1 below shows the distribution of the subjects according to age and Status.

Table 1 Distribution of Subjects According to age and Status

\begin{tabular}{lcccc}
\hline $\begin{array}{l}\text { Age } \\
(\mathbf{y r} .)\end{array}$ & $\begin{array}{c}\text { Student No } \\
(\boldsymbol{\%})\end{array}$ & $\begin{array}{c}\text { Non-student } \\
\text { No (\%) }\end{array}$ & $\begin{array}{c}\text { Control No } \\
(\mathbf{\%})\end{array}$ & $\begin{array}{c}\text { Total No } \\
(\mathbf{\%})\end{array}$ \\
\hline $\mathbf{1 6 - 2 1}$ & $15(21.42 \%)$ & $25(35.71 \%)$ & $0(0 \%)$ & $40(23.53 \%)$ \\
$\mathbf{2 2}-\mathbf{2 7}$ & $55(78.57 \%)$ & $30(42.85 \%)$ & $0(0 \%)$ & $85(50.00 \%)$ \\
$\mathbf{2 8}-\mathbf{3 3}$ & $0(0 \%)$ & $15(21.42 \%)$ & $30(100 \%)$ & $45(26.47 \%)$ \\
Total & $70(100 \%)$ & $70(100 \%)$ & $30(100 \%)$ & $170(100 \%)$ \\
\hline
\end{tabular}

The age group $16-21,22-27,28-33$ years accounted for $23.53 \%, 50.00 \%$ and $26.46 \%$ respectively. The ages $22-27(50.00 \%)$ were the dominant age group in the study.

Table 2 Distribution of positive subjects with respect to age and type of subject population

\begin{tabular}{lcccccccc}
\hline \multirow{2}{*}{ Age (yr.) } & \multicolumn{2}{c}{ Students } & \multicolumn{2}{c}{ Non-students } & \multicolumn{2}{c}{ Control group } & \multicolumn{2}{c}{ Chlamydia trachomatis Antigen } \\
\cline { 2 - 8 } & Positive & Negative & Positive & Negative & Positive & Negative & Positive & Negative \\
\hline $\mathbf{1 6}-\mathbf{2 1}$ & 3 & 12 & 0 & 25 & 0 & 0 & 3 & 37 \\
$\mathbf{2 2} \mathbf{- 2 7}$ & 8 & 47 & 0 & 30 & 0 & 0 & 8 & 77 \\
$\mathbf{2 8}-\mathbf{3 3}$ & 0 & 0 & 0 & 15 & 0 & 30 & 0 & 45 \\
Total & 11 & 59 & 0 & 70 & 0 & 30 & 11 & 170 \\
\hline
\end{tabular}

The prevalence of positive chlamydia antigen with respect to age in relation to the type of subject population is shown in table 2. The positive subjects were all from the student group population. The age with the highest prevalence $22-28$ within the student population was $8(5.71 \%)$ and $16-213(2.14 \%)$, which totaled to $11(7.85 \%)$ of the subjects. 


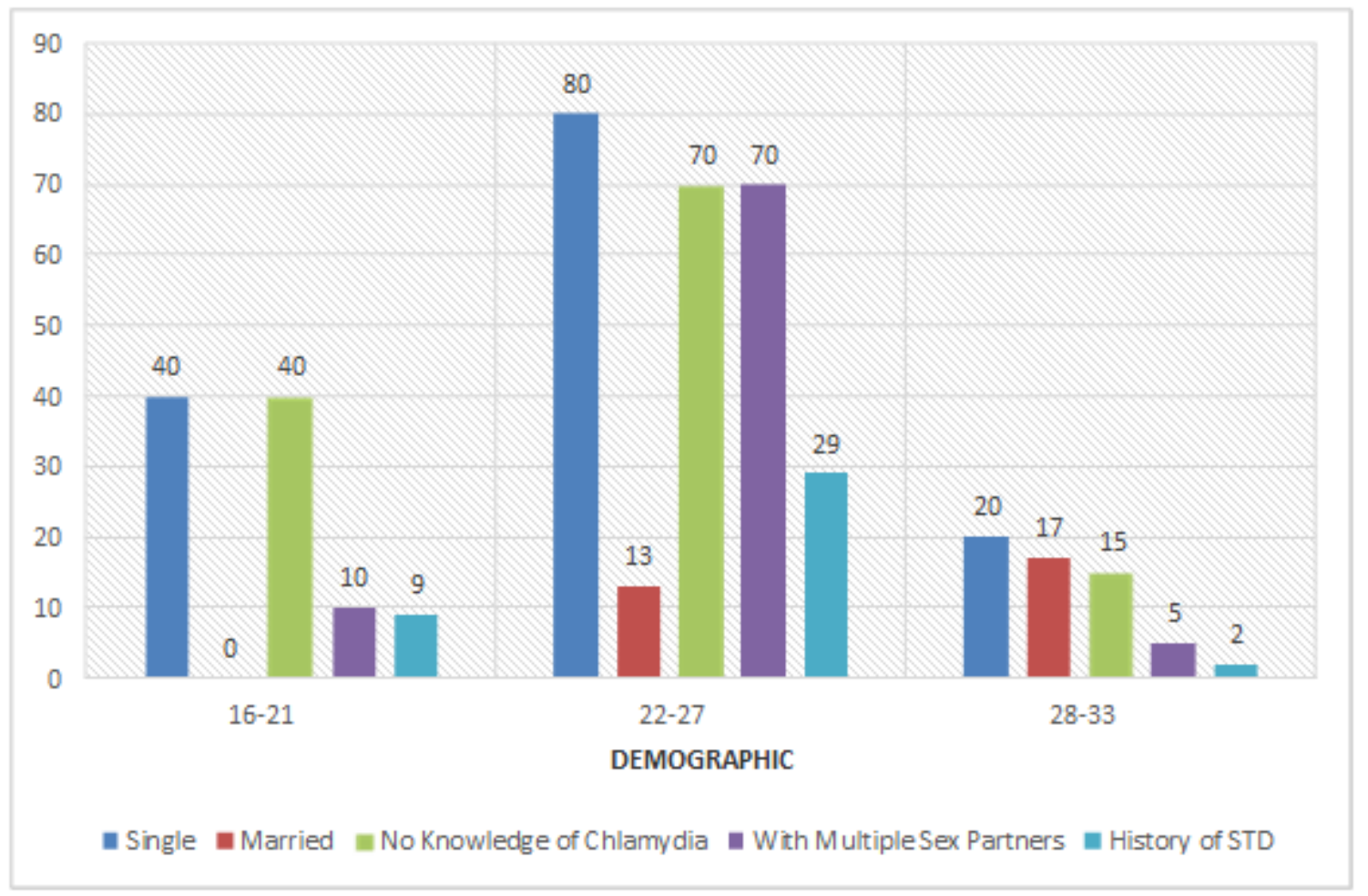

Figure 1 Demographic information of subjects with respect to age

Figure 1 above shows demographic information of subjects. A total of 140 (82.35 $\%)$ subjects were single while $30(17.65 \%)$ were married with the age group 22 27 having the highest number of single subjects. History of STD showed that 40 (23.63\%) had a history of STD (not chlamydia). 85 (50.00\%) subjects admitted to having multiple sexual partners with the highest number occurring within age group of $22-27$ and least $5(4.12 \%)$ in the age group 28-33 years. The total number of subjects with chlamydia awareness were $45(26.47 \%)$ of the total population.

Table 3 Positive subjects after Seven (7) days of treatment with doxycycline

\begin{tabular}{lll}
\hline Positive subjects & Diaspot rapid test kit & Abon rapid test kit \\
\hline P1 & Negative & Negative \\
P2 & Negative & Negative \\
P3 & Negative & Negative \\
P4 & Negative & Negative \\
P5 & Negative & Negative \\
P6 & Negative & Negative \\
P7 & Negative & Negative \\
P8 & Negative & Negative \\
P9 & Negative & Negative \\
P10 & Negative & Negative \\
P11 & Negative & Negative \\
\hline
\end{tabular}

A follow-up of the positive subjects after a treatment regime of doxycycline for Seven (7) days showed the effectiveness of antibiotics in the treatment of chlamydia, the subjects tested negative on a second test using both brands of chlamydia rapid test kit. Table 3 shows the result of subjects after Seven (7) days of treatment with doxycycline.

\section{DISCUSSION}

Chlamydia has been recognized as a highly prevalent Sexually Transmitted Diseases whose primary infections are sometime difficult to recognize as a result of its often-asymptomatic nature. It has been known to cause severe to permanent damage to a woman's reproductive system ranging from difficulty or inability to get pregnant to fatal ectopic pregnancy. The prevalence $(7.33 \%)$ of $C$. trachomatis in the study population was considerably lower to similar studies by
Ikeme et al., (29.4\%) from 136 undergraduate female students in Enugu CITATION $19 \vee 1033$ (Ikeme et al., 2011), (33\%) in asymptomatic volunteers CITATION $19 \vee 1033$ (Nwanguma et al., 2009) $56.1 \%$ in Jos Plateau CITATION $19 \vee 1033$ (Mawak et al., 2011), prevalence of 51\% among pregnant women attending antenatal clinic in Lagos state CITATION $19 \mathrm{~V} 1033$ (Okoror et al., 2008). The low prevalence may not be unconnected to the location of the study and the choice of test method (point of care testing in a resource limited setting).

The prevalence of Chlamydia infection has been known to vary depending on the population studied and laboratory method of analysis used CITATION $19 \mathrm{~V}$ 1033 (Buve et al., 2001) . The prevalence was higher in subjects with multiple sexual partners within the student population $(46.67 \%)$, was higher. The prevalence is believed to be higher in the student population because it is mostly made up of high-risk individuals. The students are 25 years old or younger and have new or multiple sexual partners amongst other factors. The high prevalence of chlamydia among young people is also indicative of the multiple barriers to accessing STD prevention services by this demographic CITATION $19 \mathrm{~V} 1033$ (Kraut-Becher \& Aral, 2003; Elliott \& Larson, 2004) . In fact, any sexually active person can be infected with chlamydia which is a very common STD among young people CITATION $19 \vee 1033$ (CDC, 2018) Torrone et al., 2007, estimated that 1 in 20 sexually active young women aged $14-24$ years have chlamydia.

It is also difficult to establish the actual prevalence of Chlamydia infection in resource limited areas as seen in developing countries due to many factors like the method of screening, the socio-cultural inhibition that prevents women from reporting sexual symptoms, the non-availability of facility to detect the organism in many health clinics and the asymptomatic nature of the disease CITATION 19 $\checkmark 1033$ (Okonofua et al., 1995; Harry et al., 1994) The fact that there is no formal $C$. trachomatis screening programmes contributes to the higher prevalence, limited active chlamydia diagnosis and specific treatment. The implication of this is that it can lead to surprisingly high levels of prevalence as a result of the asymptomatic nature of the infection and its persistent nature for months and years if not treated.

\section{CONCLUSION}


The observed prevalence reflects in the study area indicates that much still needs to be done regarding chlamydia infection.it is also an indication of the limited access and use of chlamydia specific screening and management. Since chlamydia screening is a continuous public health intervention, screening programmes should ensure ongoing regular chlamydia screening for a high proportion of the target population, and ensure that there are methods for monitoring this, and taking action if standards are not met. Changing the way that health services are organized can contribute to increasing the uptake of opportunistic screening interventions. Latex male condoms, when used consistently and correctly has proven to be effective in the past.

\section{REFERENCES}

Batteiger, B. E., Tu, W., Ofner, S., Van Der Pol, Stothard, D. R., Orr, D. P., Katz, B. P., \& Fortenberry, J. D. (2010). Repeated Chlamydia trachomatis Genital Infections in Adolescent Women. Journal of Infectious Diseases, 201, 42-51. HYPERLINK "https://doi.org/10.1086/648734" https://doi.org/10.1086/648734 Buve, A., Weiss, H.A., Lega, M., Van Dyck, E., Musonda, R., \& Zekeng, L. (2001). The Epidemiology of Gonorrhoea, Chlamydia Infection and Syphilis in Four African Countries. AID, 15, 578 - 88. https://doi.org/10.4103/0300$\underline{1652.128147}$

CDC (2017). Sexually Transmitted Disease Surveillance, 2017. Atlanta, GA: Department of Health and Human Services; September 2018. https://www.cdc.gov/std/stats17/default.htm

CDC (2018). Sexually Transmitted Disease Surveillance. Atlanta, GA: Department of Health and Human Services 2019. https://www.cdc.gov/std/stats18/STDSurveillance2018-full-report.pdf

Detels, R., Green, A. M., Klausner, J. D., Katzenstein, D., Gaydos, C., Handsfield, H., Pequegnat, W., Mayer, K., Hartwell, T. D., \& Quinn, T. C. (2011). The Incidence and Correlates of Symptomatic and Asymptomatic Chlamydia trachomatis and Neisseria gonorrhoeae Infections in Selected Populations in Five Countries. Sexually Transmitted Diseases, 38, 503. https://www.ncbi.nlm.nih.gov/pmc/articles/PMC3408314/

Elliott, B.A., Larson, J.T. (2004). Adolescents in Mid-Sized and Rural Communities: Foregone Care, Perceived Barriers, and Risk Factors. The Journal of Adolescent Health: Official Publication of The Society for Adolescent Medicine, 35, 303-309. https://doi.org/10.1016/j.jadohealth.2003.09.015

Geisler, W. M., Wang, C., Morrison, S. G., Black, C. M., Bandea, C. I., \& Hook, E. W. (2008). The Natural History of Untreated Chlamydia trachomatis Infection in The Interval Between Screening and Returning for Treatment. Sexually Transmitted Diseases, 35, 119. https://doi.org/10.1097/OLQ.0b013e318151497d Greer, L. And Wendel, G. D. Jnr (2008). Rapid Diagnostic Methods in Sexually Transmitted Infections. Infectious Disease Clinics North America, 22, 601. https://doi.org/10.1016/j.idc.2008.05.010

Harry, T.C., Saravanamuttu, K.M., Rashid, S., \& Shrestha, T.L. (1994). Audit Evaluating the Value of Routine Screening of Chlamydia trachomatis Urethral Infections in Men. Int $J$ STD AIDS, 5(5), $374 \quad-375$. https://doi.org/10.1177/095646249400500520

Høie, S, Knudsen, L. S., \& Gerstoft, J. (2011). Lymphogranuloma Venereum Proctitis: A Differential Diagnosis to Inflammatory Bowel Disease. Scandinavian $\begin{array}{llll}\text { Journal of } & \text { Gastroenterology, } & 46, & 503.11 .\end{array}$ https://doi.org/10.3109/00365521.2010.537681

Igietseme, J. U., Eko, F. O., \& Black, C. M. (2011). Chlamydia Vaccines: Recent Developments and Role of Adjuvants in Future Formulations. Expert Reviews of Vaccines, 10(11), 1585-1596. https://doi.org/10.1586/erv.11.139

Ikeme, A. C., Ezegwui, H. U., Ikeako, L. C., Agbata, I., \& Agbata, E. (2011). Seroprevalence Of Chlamydia trachomatis in Enugu, Nigeria. Niger J Clin Pract., 14, 176-180. https://doi.org/10.4103/1119-3077.84010

Ingalis, R. R., Rice, P. A., Qureshi, N., Takayama, K., Lin, J. S., \& Golenback, D. T. (1995). The Inflammatory Cytokine Response to Chlamydia trachomatis Infection Is Endotoxin Mediated. Infection and Immunity, 63, 3125-3130. https://www.ncbi.nlm.nih.gov/pmc/articles/PMC173426/

Kraut-Becher, J.R., \& Aral, S.O. (2003). Gap Length: An Important Factor in Sexually Transmitted Disease Transmission. Sexually transmitted diseases, 30, 221-225. https://doi.org/10.1097/00007435-200303000-00009

Landers, D. V., Wiesenfeld, H. C., Heine, R. P., Krohn, M. A., \& Hillier, S.L. (2004). Predictive Value of The Clinical Diagnosis of Lower Genital Tract Infection in Women. Am J Obstet Gynecol., 190, $1004-1010$. https://doi.org/10.1016/j.ajog.2004.02.015
Marrazzo, J. M., Johnson, R. E., Green, T. A., Stamm, W. E., Schachter, J., Bolan, G., Hook, E. W., Jones, R. B., Martin, D. H., St Louis, M. E., \& Black, C. M. (2005). Impact of Patient Characteristics on Performance of Nucleic Acid Amplification Tests and DNA Probe for Detection of Chlamydia trachomatis In Women with Genital Infections. Journal of Clinical Microbiology, 43, 577. https://doi.org/10.1128/JCM.43.2.577-584.2005

Mawak, J.D., Dashe, N., Agabi, Y.A., \& Panshak, B.W. (2011). Prevalence of Genital Chlamydia trachomatis Infection Among Gynecology Clinic Attendees in Jos, Nigeria. Shiraz E-Medical J., $12, \quad 2$. https://sites.kowsarpub.com/semj/articles/78511.html

Nadala, E. C., Goh, B. T., Magbanua, J. P., Barber, P., Swain, A., Alexander, S., Laitila, V., Michel, C. E., Mahilum-Tapay, L., Ushiro-Lumb, \& Lee, H. H. (2009). Performance Evaluation of a New Rapid Urine Test for Chlamydia in Men: Prospective Cohort Study. British Medical Journal, 339, b2655. https://doi.org/10.1136/bmj.b2655

Nwanguma, B., Kalu, I., \& Ezeanyika, L. (2009). Seroprevalence of AntiChlamydia trachomatis IgA Antibody in A Nigeria Population: Diagnostic Significance and Implication for The Heterosexual Transmission of HIV. The Internet Journal of Infectious Disease, 7:2. http://ispub.com/IJID/7/2/5861

O'Farrell. N., Morison, L., \& Moodley, P. (2008). Genital Ulcers and Concomitant Complaints in Men Attending A Sexually Transmitted Infections Clinic: Implications for Sexually Transmitted Infections Management. Sexually Transmitted Diseases, 35:545-9. https://doi.org/10.1097/OLQ.0b013e31816a4f2e Okonofua, F.E., Ako-Nai, K.A., \& Dighitoghi, M.D. (1995). Lower Genital Tract Infections in Infertile Nigerian Women Compared with Controls. Genitourin Med., 71(3):163-8. https://doi.org/10.1136/sti.71.3.163

Okoror, L. E., Agbonlahor, D. E., Esumeh, F. I. \& Umolu, P. I. (2007). Prevalence of Chlamydia in Patients Attending Gynecology Clinics in SouthEastern Nigeria. African health sciences, 7(1), 18-24. https://www.ncbi.nlm.nih.gov/pmc/articles/PMC2366126/

Okoror, L.E., Omilabu, S.A., Orue, P. O., \& Ajayi, G. (2008). Seroepidemiological Survey of Chlamydia in Patients Attending Pre- and PostNatal Clinic at The College of Medicine of The University of Lagos, Nigeria. The open Tropical medicine Journal, 1, 83-86. https://doi.org/10.2174/1874315300801010083

Rours, G. I., Duijts, L., Moll, H. A., Ingrid G, Arends L. R., Ronald de Groot, Jaddoe V. W., Hofman A, Steergers E. A. P., Mackenbach J. P., Ott A, Willemse H. F. M., Van Der Zwaan E. A. E., Verkooijen R. P., \& Verbrugh H. A. (2011). Chlamydia trachomatis Infection During Pregnancy Associated with Preterm Delivery: A Population-Based Prospective Cohort Study. European Journal of Epidemiology, 26: 493. https://doi.org/10.1007/s10654-011-9586-1

Severin, J. A., \& Ossewaarde J. M. (2006). Innate Immunity in Defense Against Chlamydia trachomatis Infections. Drugs Today, 42,75-81. https://pubmed.ncbi.nlm.nih.gov/16683047/

Stamm, W. E., Jones, R. B., \& Batteiger, B. E. (2005). Chlamydia trachomatis (Trachoma, Perinatal Infections, Lymphogranuloma Venereum, And Other Genital Infections. In: Principles and Practice of Infectious Disease, 6th edition, Mandell G. L., Bennett J. E. and Dolin R. (Eds). Elsevier, 2, 2239-2255. HYPERLINK "https://doi.org/10.1016/B978-1-4557-4801-3.00182-X" lo "Persistent link using digital object identifier" It "_blank" https://doi.org/10.1016/B978-1-4557-4801-3.00182-X

Torrone, E., Papp, J., \& Weinstock, H. (2007). Prevalence of Chlamydia trachomatis Genital Infection Among Persons Aged 14-39 Years - United States, 2007-2012. $\quad$ MMWR, 63, 834-8. https://www.ncbi.nlm.nih.gov/pmc/articles/PMC4584673/

Ward, H., Alexander, S., Carder, C., Dean, G., French, P., Ivens, D., Ling, C., Paul, J., Tong, W., White, J., \& Ison, C. A. (2009). The Prevalence of Lymphogranuloma Venereum Infection in Men Who Have Sex with Men: Results of A Multicentre Case Finding Study. Sexually Transmitted Infections, 85, 173. https://doi.org/10.1136/sti.2008.035311

White, J. A. (2009). Manifestations and Management of Lymphogranuloma Venereum. Current opinion in infectious diseases, 22, 57-66. https://doi.org/10.1097/QCO.0b013e328320a8ae 